\title{
Adolescents' experiences and perceived (dis)advantages of the three main outlet types for alcohol purchases
}

Journal of Health Psychology $1-10$

(c) The Author(s) 2015

Reprints and permissions: sagepub.co.uk/journalsPermissions.nav DOI: $10.1177 / 1359105315592046$ hpq.sagepub.com

@SAGE

\author{
Jordy F Gosselt, Tanja Strump and \\ Joris Van Hoof
}

\begin{abstract}
Based on the existing literature, relevant determinants of availability for on-premises locations, off-premises locations, and the Internet were qualitatively explored and categorized by "experts" consisting of underage alcohol purchasers. In total, 14 focus group discussions were conducted with 94 Dutch adolescents. For onpremises locations, the high prices were perceived as the biggest disadvantage, and the ease to circumvent legal age limits as the biggest advantage. For off-premises locations, the cheap pricing was perceived as the most positive aspect, and the legal age limit as the biggest disadvantage. For online purchases, the waiting time was perceived as the most negative aspect, and the proximity of online stores as the biggest advantage.
\end{abstract}

\section{Keywords}

adolescents, alcohol availability, alcohol obtaining, off premises, on premises, online

\section{Introduction}

Adolescent alcohol consumption is a welldiscussed topic in societies, including the Dutch society. The Netherlands is third on the European list of countries regarding the percentage of adolescents consuming alcohol five times or more during the last 4 weeks (Soellner et al., 2014). The use of alcohol by adolescents is influenced by various factors including marketing and advertisement strategies (Cheng et al., 2011), and sociocultural and attitudinal factors (Petraitis et al., 1995). However, one of the most important influencing factors and a reliable predictor of alcohol use intention is the "availability of alcohol" (Van Hoof et al., 2010a). In addition to social sources (Hearst et al., 2007), adolescents may obtain alcoholcontaining products from various commercial sources, which can be categorized into three domains: on-premises outlets, off-premises outlets, and the Internet.

At on-premises outlets, such as restaurants, bars, and festivals, alcohol can be bought and beverages are meant to be consumed on the spot. The second purchase domain concerns off-premises outlets, like supermarkets and liquor stores, where alcohol can be bought for use

University of Twente, The Netherlands

\section{Corresponding author:}

Jordy F Gosselt, Department of Communication Studies, Faculty of Behavioral Sciences, University of Twente, PO Box 217, 7500 AE Enschede, The Netherlands.

Email: j.f.gosselt@utwente.nl 
at another location. Finally, the Internet is a source of increased importance when it comes to alcohol sales. Specialized Alcohol Home Delivery Services (AHDSs) are available, and various websites offer beverages in their online shops (e.g. grocery stores, liquor stores, specialized wine and beer stores, and online marketplaces). Nowadays, it is possible to order alcohol online, "increasing youths' exposure to opportunities to buy alcohol online" (Williams, 2013: 1346). Research on the purchase of other risk products, like tobacco, shows that adolescents are likely to engage in online shopping (Mutschler et al., 2007). However, it is still unclear whether and why adolescents purchase alcohol on the Internet and which factors influence their decision where to buy: off premises, on premises, or online (Williams and Ribisl, 2012).

Availability as a concept can be differentiated into four kinds (Van Hoof et al., 2010c): physical availability, economic availability, legal availability, and social availability. Determinants of physical availability influencing alcohol purchase include opening hours (Stanley et al., 2010), outlet density (Young et al., 2013), outlet proximity (Halonen et al., 2013; Young et al., 2013), delivery policies (including delivery methods and delivery restrictions, like shipping restrictions to local or national areas; Chen et al., 2014; Pozzi, 2013), and product variety (Liu and Forsythe, 2010). Second, economic availability depends on the product price (Van Hoof et al., 2010c) including additional costs like taxes, entrance or wardrobe deposit fees, and delivery costs (Van Hoof et al., 2010c), and minimum purchase quantity in case of online purchases (Fix et al., 2006). Third, legal availability is determined by age limits for sales, possession or consumption (Jackson et al., 2014), legal restrictions to adolescents and/or vendors (Gosselt et al., 2011, 2012), age verification activities (Van Hoof et al., 2010b; Wolff et al, 2011), and vendor compliance (Van Hoof et al., 2011). Finally, social availability is determined by secondary purchasing (purchase by older friends or parents; Gosselt et al., 2012), shoulder tapping (adolescents asking strangers or other customers to purchase alcohol for them; Fabian et al., 2008), and familiarity with vendors (Gosselt et al., 2012).

As can be seen, years of research informed us about the many factors that influence (perceived) availability of alcoholic products and consequently affect purchase behavior and consumption. However, it is unclear how underage adolescents experience the various types of availability when buying alcohol and what the most prominent availability factors are according to them. Therefore, this study explores the role of the four types of availability for onpremises, off-premises, and online alcohol purchases. The latter category has never been studied within this domain (Holmes et al., 2014), despite the fact that the Internet is a commonly used medium among adolescents, and increasingly popular for alcohol purchases.

\section{Methods}

For this exploratory study, focus group sessions with underage students were used. In total, 14 focus group discussions of 55-65 minutes were conducted, with an average of six students (total $N=94$ ). Moderately, structured group discussions allowed the researchers to retrieve new information and allowed the participants to share individual experiences and opinions (Kamarulzaman, 2011).

\section{Procedure}

Since the focus groups were conducted with adolescent participants, special attention was paid to the moderation of the discussion. According to Vaughn et al. (1996), activities like writing during the focus group session could help to gain and maintain attention. Also, visualization is a recommended tool for working with adolescents, due to the facilitated mode of perception and imagination, and the simplification of complex information (Clark, 2011). Therefore, a modified version of the "card game" (Robinson, 1999) was used: Group members were divided into subgroups of two or three participants, depending on the total number of participants in the 
focus group. At a central place in the classroom, a poster was installed with blank columns for positive/negative aspects for each purchase domain. Instead of receiving a set of statements, each team received an unlimited amount of blank paper cards, and the participants were instructed to individually fill out their opinions and thoughts concerning the different domains. Participants were free to add as many notes as they wanted to. Similar to an Interactive Quality Analysis (IQA) focus group study (Northcutt and McCoy, 2004), the focus groups thus started with a short, individual brainstorming session in the subgroups, after which the teams categorized their notes on the table, resulting in a visual overview of their opinions and experiences. This order guaranteed that thoughts of the participants were not influenced by a prior whole-group discussion. Additionally, the final table content that was created allowed for a cross comparison between the groups.

All focus group sessions had the same structure. First, an introduction of the moderator (second author of this article) and the research project were given, in which was explained that the participants were going to be asked to share their opinion(s) and experience(s) regarding alcohol purchase. After all participants had introduced themselves, they received a deck of empty cards and were asked to write down all their opinions and experiences regarding alcohol purchase in on-premises outlets, off-premises outlets, and online. When all teams were finished, a group discussion started. Based on the table content provided, each team first explained their cards and then compared them with the opinions and experiences of the other teams. Participants were asked to explain their cards and to compare these with the other purchase domains. To achieve this, open-ended questions were asked by the moderator, such as "What do you mean by this?" "Could you elaborate?" and "What do you think about this?" Furthermore, the determinants described in the theoretical framework were used as a guideline for further discussion topics. After the discussion, the researcher ended with a final conclusion for all participants to reflect upon and asked the participants to fill out a survey to collect demographic data. The Ethical Committee of the Faculty of Behavioral Sciences of the University of Twente (the Netherlands) approved the study.

\section{Participants}

Seven secondary schools from a total of 418 schools agreed to participate in this study. Teachers were instructed to randomly select pupils. The only requirement all selected participants had to meet was having some experience with buying alcohol from at least one of the three purchase domains. Because all participants were minors, parents were asked for informed consent. If parents did not agree with participation, pupils were not allowed to take part. In order to compare between legal and illegal alcohol purchases, two age groups were included (14-15 years, $n=40$; $16-17$ years, $n=54$; mean age $=15.8$ years $)$. The participants attended one of three educational levels (lower vocational education, $n=44$; higher general secondary education, $n=23$; pre-university education, $n=27)$, and both girls $(n=54)$ and boys $(n=40)$ participated. At the time, the study was conducted (late 2013), the legal age limit to purchase alcohol was 16 years for beers and drinks containing up to 15 percent of alcohol, and 18 years for drinks containing 15 percent of alcohol or more. The majority of the participants indicated to only consume alcohol on the weekends, especially on Saturdays. Almost 40 percent of the participants indicated to drink 3-5 glasses of alcoholic drinks, and about 25 percent indicated to drink 6-10 glasses.

\section{Analysis}

All group discussions were recorded on video, transcribed, and then coded and analyzed using Atlas.ti, version 16.2. Based on our conceptual framework, including the four types of availability, a codebook was designed. Subsequently, a top-down qualitative analysis of the interviews was organized by two extensively trained coders, to uncover the main topics and categories 
Table I. Number of cards assigned per purchase domain regarding the four types of availability.

\begin{tabular}{|c|c|c|c|c|}
\hline & On premises & Off premises & Online & Total \\
\hline \multicolumn{5}{|l|}{ Physical availability } \\
\hline Product variety & 2 & 18 & 15 & 35 \\
\hline Waiting time & 8 & 5 & 15 & 28 \\
\hline Proximity & 4 & 3 & 12 & 19 \\
\hline Delivery policy & 0 & 0 & 8 & 8 \\
\hline Location of consumption & 0 & 3 & 0 & 3 \\
\hline Opening hours & 0 & 1 & I & 2 \\
\hline Total physical & 14 & 30 & 51 & 95 \\
\hline \multicolumn{5}{|l|}{ Legal availability } \\
\hline Age verification by vendors & 32 & 26 & 17 & 75 \\
\hline Legal restrictions & 7 & 5 & 1 & 13 \\
\hline Types of age verification & 0 & 0 & I & 1 \\
\hline Total legal & 39 & 31 & 19 & 89 \\
\hline \multicolumn{5}{|l|}{ Economic availability } \\
\hline Product price & 27 & 33 & 18 & 78 \\
\hline Price comparisons & 0 & 3 & 0 & 3 \\
\hline Minimum purchase quantity & 0 & 0 & 2 & 2 \\
\hline Total economic & 27 & 36 & 20 & 83 \\
\hline \multicolumn{5}{|l|}{ Social availability } \\
\hline Familiarity with vendors & 1 & 4 & 9 & 14 \\
\hline Secondary purchasing & 2 & 4 & 2 & 8 \\
\hline Shoulder tapping & I & 0 & 0 & 1 \\
\hline Total social & 4 & 8 & 11 & 23 \\
\hline
\end{tabular}

mentioned by the participants. An interrater reliability comparison was performed by the two coders based on 10 percent of the data. Several rounds of coding resulted into a reliable coding scheme (Cohen’s Kappa $=.88)$.

\section{Results}

In this section, the results of the focus group sessions are described per availability type. Table 1 summarizes the number of cards that the adolescents assigned to the four types of availability. Each card served as input for further discussion.

\section{Physical availability of alcohol}

Most comments were made regarding the physical availability of alcohol. First, the product variety strongly influenced the choice for a specific purchase domain. According to the adolescents, product variety is a strong advantage of offpremises locations and the Internet: Many other (non-alcoholic) products can be obtained at offpremises locations (e.g. supermarkets) and a great assortment is provided on the Internet. Second, the proximity refers to the physical distance of a domain and the alcoholic beverages. Many participants were not likely to order online, because of a high proximity of physical locations within their living environment: "Honestly, I've never thought about the Internet that way. It didn't cross my mind, because there's always a grocery store nearby" (girl, 17 years). However, in general, the extent of age verification and product price were more important than the outlet density. Especially, younger participants remarked that they had to walk in public to reach grocery stores and thus feared police controls on their way. Some adolescents were willing to travel a longer distance to overcome the obstacles of expected age verification and (high) 
product price. Third, although the delivery option of the Internet provided some advantages to the participants, it involved disadvantages as well. Especially, the delivery moment itself was found to be critical if parents were home and relational consequences could occur. Fourth, while beverages at on-premises locations have to be consumed on the spot, purchased products from off-premises locations and the Internet enable consumption at different locations. Participants considered this an advantage: Beverages were often consumed at their own or a friend's home before going out (pre-drinking), after which adolescents did not feel the need to purchase many drinks at on-premises locations, so they saved money. Fifth, the opening hours of off-premises locations were regarded as a negative aspect: Participants considered the openings hours of grocery and liquor stores limited. Because the Internet is always accessible, it is regarded as a complement to off-premises locations, minding that the delivery time has to be taken into consideration, so spontaneous purchases are difficult. Finally, even though not all participants had bought alcohol online, the adolescents mentioned that the waiting time between product order and product receipt is the most important threshold to ordering online. Although this issue has not been mentioned before as an aspect of physical availability, we present it here. Participants considered online ordering difficult and unpractical with no possibility for spontaneous purchases: "... [during the delivery time] you could've walked to the grocery store several times" (girl, 16 years). Therefore, off-premises locations like grocery and liquor stores were more attractive to most of the participants: "You can just walk there. [...] At the grocery store, you can pick it up easily" (boy, 14 years). On-premises locations featured the shortest waiting time and were considered very convenient: Drinks could be refilled quickly and consumed quite quickly.

\section{Legal availability of alcohol}

The second most discussed type of availability concerns the legal availability. Legal availability for on-premises locations and the Internet was judged high, since alcohol is available despite being too young. Legal availability of off-premises locations was judged to be more difficult: in off-premises outlets, age validation was perceived more strict. This was strongly influenced by the experienced and expected age verification by vendors, which was the most important determinant of legal availability. According to many participants, vendors would sell beverages to adolescents just to make money and they hardly verify the customers' age in crowded situations. In addition to the group of vendors selling alcohol to adolescents, another group of personnel was described as important: security personnel, who often verify people's age at the entrance of festivals, clubs, or pubs, "because most of the pubs are for people aged 16 and up. They ask for our age when we order liquors, but they sell beer without verifying our age, because security staff already let us in" (girl, 15 years). In general, the adolescents reported a chance of multiple age verification moments, for example at the entrance and at the bar, but this was not perceived as a threshold for visiting on-premises locations. For offpremises locations, nearly all groups described strict age verification at grocery and liquor stores. Therefore, the adolescents were not likely to attempt purchasing beverages at offpremises locations, as they would feel ashamed in front of vendors, other customers, and peers. To overcome the age verifications at off-premises and on-premises locations, some participants mentioned the possibility of using a false ID or borrowing the ID from older friends or siblings. Others described tricks for purchasing alcohol, such as taking a motorbike helmet to an off-premises location to appear old enough for the legal age limit for driving a moped (minimum age: 16 years) or a motorcycle (minimum age: 18 years), and asking vendors to wrap up the purchase as a gift for another person. Regarding entering on-premises locations,

someone else takes your coat with you, gets a ticket at the wardrobe for your coat, walks back to the entrance and gives you the ticket. Then you can tell the security staff that you've already been 
checked and have entered before. Then you can just pass. It works. (girl, 15 years)

For purchases on the Internet, participants with online purchase experience described the ease of ordering because of a total lack of age verification and the entry of false data to gain anonymity. Simultaneously, participants were well informed about the legal restrictions to alcohol purchase and use: some adolescents feared police controls after their (illegal) purchase at on- and off-premises locations, and being punished for offending the legal prescriptions. Regarding online purchases, respondents worried about the possibilities for online age verification. They feared that age and purchase was controllable by personal bank information (e.g. PayPal accounts) or other methods (e.g. age verification at delivery).

\section{Economic availability of alcohol}

The most important economic determinant was considered the product price, which was based on the relationship between beverage content and price. The participants agreed that buying beverages at on-premises locations was expensive, while more could be purchased for less money at grocery stores, especially when beverages were on sale. Additionally, participants often chose cheaper imitation products of well-known brands. This strongly influenced their choice for an offpremises location: especially, grocery stores were favored over liquor stores. Consequently, adolescents often bought beverages at off-premises locations and used them for pre-drinking purposes before visiting on-premises locations. Concerning the Internet, the expected product price differed among the participants: some expected products to be cheaper while others expected higher total costs compared to on- and off-premises locations. They remarked that additional costs for the delivery of online purchased products would increase the total product price for online orders. Besides, additional costs were also mentioned as a negative aspect of on-premises locations: often, entrance or wardrobe fees had to be paid. In general, participants used price comparisons to compare especially off-premises stores, on-premises locations, and the Internet with each other, more so than alcohol outlets within the same domain. For example, participants tended to compare festivals with supermarkets, but did not compare different supermarkets or different websites with each other. For the Internet, some participants thought of price reductions for ordering more products simultaneously, but their limited financial budget would inhibit orders with minimum purchase quantities. Another threshold for online ordering was related to the paying methods: the required paying methods (e.g. PayPal, credit, or debit cards) were often not accessible to adolescents. Additionally, parents had to give admission to online banking or would receive copies of the bank statements.

\section{Social availability of alcohol}

Most comments regarding the social availability of alcohol referred to familiarity with vendors. Although in the previous literature, social availability only refers to availability of alcohol through friends or family members, we also consider alcohol through befriended vendors, an aspect of social availability. According to most participants, friends working at supermarkets could easily sell beverages to minor friends. However, as their friends could lose their jobs as cashiers because of strict vendor controls at supermarkets, this rarely takes place. Furthermore, knowing (security) staff personally led to fewer age verifications and enabled entering on-premises locations without age verifications: "It's all about nepotism" (girl, 17 years). In general, once adolescents were able to enter the on-premises location, buying alcohol was not difficult anymore because bar tenders seem to rely on age verification at the entrance. Second, regarding secondary purchasing; due to the common habit of predrinking, adolescents were in need of purchasing drinks at supermarkets or liquor stores. Because age verifications at supermarkets were very often considered strict, secondary purchasing of beverages was described as a rather frequently used method to overcome this "problem." The secondary purchasers could be split up into two groups. 
First, family members of the participants, especially parents and older brothers and/or sisters, engaged in secondary purchasing of beverages regularly. Adolescents described that their parents "could hold a bit of control over the quality and amount of beverages consumed" (girl, 15 years) by buying the alcoholic drinks for them. The second group of secondary purchasers consisted of older friends who bought the drinks for their minor friends. Finally, in contrast to secondary purchasing, shoulder tapping was less preferred: participants were not likely to "ask a stranger to get some drinks" (girl, 16 years). Only one participant said it was an option to ask strangers to buy a drink at on-premises locations.

\section{Most prominent availability types per outlet}

Based on the discussions with the adolescents, the three most important availabilities for each purchase domain will now be discussed (for an overview, see the Supplementary Material online). It is noticeable that the first two determinants for onand off-premises locations are the same, but judged reversely. Participants considered product price as the most important determinant for purchasing beverages at on- and off-premises locations, which had a direct relation with drinking behavior. The high price at on-premises locations led to fewer alcohol purchases and less alcohol consumption. Therefore, adolescents favored offpremises stores due to lower product prices and the possibility of purchasing low-priced imitation products, which often led to pre-drinking before going out, which was described as a common habit to save money on alcoholic drinks. Underage participants reported to use tricks to appear older in stores, such as carrying a moped helmet (legal at 16 years, same age as for beers).

Second, for both premises types, the legal availability was found to be an important threshold to alcohol purchases: the extent of age verification determined the choice for specific locations. Especially, at off-premises stores, strict age verification was perceived as a big threshold to adolescents. In contrast, for on-premises locations, adolescents experienced poor age verifications, although multiple age verification moments were possible (i.e. entrance and bar). In order to enter on-premises locations, underage participants reported to use tricks here as well, such as sending in an adult friend first to hand in the coats at the wardrobe facility, and subsequently entering the bar with that wardrobe ticket to trick the bouncer into believing the minor had already been screened before delivering that coat.

For off-premises locations, regarding the physical availability (the third determinant), most of the participants agreed that off-premises locations offered a much greater product range compared to on-premises locations. Regarding on-premises locations, the actual locations themselves would simplify getting beverages due to short distances to bars (physical availability).

For the Internet, the physical availability was considered most important (determinants 1 and 2 ), followed by the economic availability (determinant 3). Participants regarded the waiting time between purchase and consumption as much longer than for on- and off-premises locations, but were positive about the high physical proximity of products; home delivery was considered advantageous if a great number of products would be ordered. Third, product price was considered important, as adolescents expected additional costs leading to a higher total product price.

\section{Discussion}

This study explored the role of categories of availability for adolescents in alcohol purchasing behavior. Our results show that determinants of, in particular, economic, legal, and physical availability are especially important for adolescents, including slight differences between individual outlets. As was shown in previous studies, high product prices at on-premises locations limit beverage purchases, and therefore, adolescents engage in pre-drinking, consuming beverages bought at off-premises locations (Williams and Schmidt, 2014). However, some results of previous studies cannot be confirmed by this study. First, participants do not directly mention the number of stores in their neighborhood (Halonen et al., 2013) as relevant, but rather the 
proximity to the stores and beverages. The presence of at least one on- and off-premises location within the adolescent's close living environment is satisfactory for the participants. Second, for online purchases, the option to indicate alternative delivery addresses (Chen et al., 2014; Pozzi, 2013) was not mentioned at all during the focus groups. Participants link the delivery option only to their home address, which is considered negatively and unpractical, especially due to determinants of social availability (parental attitude) and physical availability (proximity of off-premises locations). Third, in contrast to previous studies that predict a high appeal of online alcohol sales due to cheap alcohol prices (Williams and Schmidt, 2014), adolescents are not convinced that they are saving money by ordering online, since the addition of delivery costs leads to a higher total price than for alcohol purchases in retail stores. Fourth, multiple moments of age verification for alcohol purchases (Williams and Ribisl, 2012) were not considered important determinants by the adolescents, which differs from the results of earlier mystery shopping studies (Gosselt et al., 2011; Van Hoof and Gosselt, 2013). Participants perceive it as difficult to purchase beverages at grocery and liquor stores due to strict age verification by vendors (legal availability), which is described as an important threshold to alcohol purchase as well. Reasons for these results can be that mystery shopping research particularly focuses on the compliance of vendors without taking the experiences and opinions of adolescents into account. Finally, previous studies for other age-restricted risk products found that adolescents shop online to overcome the strict age verification in retail stores (Fix et al., 2006; Mutschler et al., 2007). This research shows that participants confirm the easy access to age-restricted alcoholic beverages online (Williams and Schmidt, 2014), although some of the adolescents, especially the younger ones with no online purchase experience, are held back by their expectation of some kind of age verification.

Incorporating the online alcohol sales as well, this study resulted in two new aspects of availability. In addition to the existing literature, the social availability domain should be extended with availability through befriended vendors. The current literature only incorporates friends and family (who set out to purchase alcohol), but vendors who sell alcohol despite the legal age limits should be added here. And second, when talking about physical availability, the time involved should be taken into account as well. Proximity, of course, relates to time investment, but when buying alcohol online, the time between the purchase and consumption turns out to be a factor of relevance. Simultaneously, the "waiting time" (Gupta et al., 2004) is regarded as the most important constraint regarding online purchasing. In general, it can be concluded that adolescents do not prefer the Internet for regular alcohol purchases; additional costs, the long waiting time, and parental attitude are the most important thresholds to online alcohol purchases.

Regarding our methodology used, it is important to consider the role of group processes in focus groups. Especially, when it concerns young participants, the interactions are not necessarily positive as intimidation and social desirability may influence the (direction of the) discussion, leading to some saying little or nothing (Greene and Hogan, 2005; Hill, 2006). However, the chosen research method and the study design proved to gather valuable data. Participants first used cards to gain ideas in small groups, resulting in multifocal and active discussion during the remainder of the sessions. Indeed, such playful group activities rather than conversation can be considered a useful tool in the case of minors (Greene and Hogan, 2005). Furthermore, the focus groups created a safe peer environment, similar to the small group settings that children are familiar with from their classroom work. Such a safe environment may encourage them to share their opinions when they hear others do so and reflect upon them (Hill et al., 1996).

With respect to the limitations of this study, two remarks should be made. Although we strived for a maximum balance regarding our sample, adolescents of 14 and 15 years with a 
pre-university education are underrepresented in this study. This may have influenced our results as educational levels are related to drinking and alcohol purchasing (Britt et al., 2006). Second, only a few participants $(n=10)$ had experience with ordering alcohol online. Therefore, the results concerning online purchases were primarily based on expectations about the process of online ordering instead of actual experiences. Nevertheless, we found that the participants used most of the developed determinants to describe their purchase preferences.

\section{Acknowledgements}

The authors would like to thank all participants and schools for taking part in this study.

\section{Funding}

This research received no specific grant from any funding agency in the public, commercial, or not-forprofit sectors.

\section{References}

Britt H, Toomey TL, Dunsmuir W, et al. (2006) Propensity for and correlates of alcohol sales to underage youth. Journal of Alcohol and Drug Education 50: 25-42.

Chen MC, Hsu CL, Hsu CM, et al. (2014) Ensuring the quality of e-shopping specialty foods through efficient logistics service. Trends in Food Science \& Technology 35: 69-82.

Cheng H, Kotler P and Lee NR (2011) Social Marketing for Public Health. Sudbury, MA: Jones \& Bartlett Publishers.

Clark CD (2011) In a Younger Voice-Doing ChildCentered Qualitative Research. New York: Oxford University Press.

Fabian LEA, Toomey TL, Lenk KM, et al. (2008) How do underage college students get alcohol? Journal of Drug Education 31: 15-26.

Fix BV, Zambon M, Higbee C, et al. (2006) Internet cigarette purchasing among $9^{\text {th }}$ grade students in Western New York: 2000-2001 vs. 2004-2005. Preventive Medicine 43: 191-195.

Gosselt JF, Van Hoof JJ and De Jong MDT (2012) Why should I comply? Sellers' accounts for (non-)compliance with legal age limits for alcohol sales. Substance Abuse Treatment, Prevention, and Policy 7: 1-12.
Gosselt JF, Van Hoof JJ, Baas N, et al. (2011) Under 20 ? Show your ID! Effects of a national information campaign on compliance with age restrictions for alcohol sales. Journal of Adolescent Health 49: 97-98.

Greene S and Hogan S (2005) Researching Children's Experience: Approaches and Methods. London: SAGE.

Gupta A, Su B and Walter Z (2004) An empirical study of consumer switching from traditional to electronic channels: A purchase decision perspective. International Journal of Electronic Commerce 8: 131-161.

Halonen JI, Kivimäki M, Virtanan M, et al. (2013) Proximity of off premise alcohol outlets and heavy alcohol consumption: A cohort study. Drug and Alcohol Dependence 132: 295-300.

Hearst MO, Fulkerson JA, Maldonado-Molina MM, et al. (2007) Who needs liquor stores when parents will do? The importance of social sources of alcohol among young urban teens. Preventive Medicine 44: 471-476.

Hill M (2006) Children's voices on ways of having a voice children's and young people's perspectives on methods used in research and consultation. Childhood 13: 69-89.

Hill M, Laybourn A and Borland M (1996) Engaging with primary-aged children about their emotions and well-being: Methodological considerations. Children and Society 10: 129144.

Holmes J, Guo Y, Maheswaran R, et al. (2014) The impact of spatial and temporal availability of alcohol on its consumption and related harms: A critical review in the context of UK licensing policies. Drug and Alcohol Review 33: 515-525.

Jackson N, Denny S, Sheridan J, et al. (2014) Predictors of drinking patterns in adolescence: A latent class analysis. Drug and Alcohol Dependence 135: 133-139.

Kamarulzaman Y (2011) A focus group study of consumer motivations for e-shopping: UK versus Malaysia. African Journal of Business Management 5: 6778-6784.

Liu C and Forsythe S (2010) Sustaining online shopping: Moderating role of online shopping motives. Journal of Internet Commerce 9: 83-103.

Mutschler J, Diehl A and Kiefer F (2007) Beschaffung psychotroper Substanzen über das Internet. Der Nervenarzt 78: 818-820. 
Northcutt N and McCoy D (2004) Interactive Qualitative Analysis-A Systems Method for Qualitative Research. Thousand Oaks, CA: SAGE.

Petraitis J, Flay BR and Miller TQ (1995) Reviewing theories of adolescent substance abuse: Organizing pieces of the puzzle. Psychological Bulletin 117: 67-86.

Pozzi A (2013) E-commerce as a stockpiling technology: Implications for consumer savings. International Journal of Industrial Organization 31: 677-689.

Robinson N (1999) Focus group methodology—With selected examples from sexual health research. Journal of Advanced Nursing 29: 905-913.

Soellner R, Göbel K, Scheithauer H, et al. (2014) Alcohol use of adolescents from 25 European countries. Journal of Public Health 22: 57-65.

Stanley LR, Henry KL and Swaim RC (2010) Physical, social and perceived availabilities of alcohol and last month alcohol use in rural and small urban communities. Journal of Youth Adolescence 40: 1203-1214.

Van Hoof JJ and Gosselt JF (2013) Underage alcohol sales-It only takes a minute: A new approach to underage alcohol availability. Journal of Studies on Alcohol and Drugs 74: 423-427.

Van Hoof JJ, Gosselt JF and De Jong MDT (2010a) Parent's opinions on youth alcohol use and governmental alcohol control policies. Health Policy 97: 195-201.

Van Hoof JJ, Gosselt JF and De Jong MDT (2010b) Shop floor compliance with age restrictions for tobacco sales: Remote versus in-store age verification. Journal of Adolescent Health 46: 197-199.

Van Hoof JJ, Gosselt JF, Baas N, et al. (2011) Improving shop floor compliance with age restrictions for alcohol sales: Effectiveness of a feedback letter intervention. European Journal of Public Health 22: 1-6.

Van Hoof JJ, Reijlink LMJ and Van Dalen WE (2010c) Alcohol outlets near schools in a midsize Romanian city: Prevalence and characteristics. Romanian Journal of Legal Medicine 18: 295-300.

Vaughn S, Schumm JS and Sinagub J (1996) Focus Group Interviews in Education and Psychology. Thousand Oaks, CA: SAGE.

Williams RS (2013) Underage Internet alcohol sales on eBay. Addiction 108: 1346-1348.

Williams RS and Ribisl KM (2012) Internet alcohol sales to minors. Archives of Pediatrics \& Adolescent Medicine 166: 808-8013.

Williams RS and Schmidt A (2014) The sales and marketing practices of English-language Internet alcohol vendors. Addiction 109: 432-439.

Wolff LS, El Ayadi AM, Lyons NJ, et al. (2011) Improving the alcohol retail environment to reduce youth access: A randomized community trial of a best practices toolkit intervention. Journal of Community Health 36(3): 357-366.

Young R, Macdonald L and Ellaway A (2013) Associations between proximity and density of local alcohol outlets and alcohol use among Scottish adolescents. Health \& Place 19: 124-130. 